\title{
PROJECT STATUS OF THE 1-GeV SNS LINAC
}

\author{
R. A. Hardekopf ${ }^{+}$, D. S. Stout, T. D. Sutton, LANL, Los Alamos, NM
}

\section{Abstract}

The U.S. Department of Energy has initiated construction of a \$1.3 B Spallation Neutron Source (SNS) to be located at Oak Ridge, Tennessee. Five national laboratories, ANL, BNL, LANL, LBNL, and ORNL are collaborating in the design and construction of this major new U.S. neutron science facility. The present design is a $60-\mathrm{Hz}, 1-\mathrm{GeV} \mathrm{H}^{-}$ linac injecting into an accumulator ring to produce pulses of $<1-\mu$ s on the neutron-producing target. The accelerator design has been refined from the CDR concept to provide improvements in assembly and maintainability. A converter-modulator design using IGBT technology replaces the conventional RF system to power the accelerating cavities. Cost estimates for the linac have utilized both accelerator modeling codes and more conventional cost-estimating approaches. Comparison of these two methods has led to increased confidence in the linac cost estimate of about $\$ 300 \mathrm{M}$ (including $\mathrm{R} \& \mathrm{D}$ and controls but without contingency). A Monte-Carlo simulation of the project cost using risk-based analysis has further contributed to the estimate and identified critical areas. The project uses Primavera Project Planner as the scheduling software. A linac R\&D program to develop key technologies is underway at Los Alamos.

\section{LINAC DESIGN}

The basic linac architecture has not changed from the CDR in June, 1997 [1]. The energy range from 2.5 to $1000 \mathrm{MeV}$ is achieved with a combination of structures: a Drift Tube Linac (DTL) up to about $20 \mathrm{MeV}$, a CoupledCavity Drift Tube Linac (CCDTL) to about $100 \mathrm{MeV}$, and a side-Coupled-Cavity Linac (CCL) to the final energy. To accommodate engineering constraints, changes to the lattice structure were made in the spring of 1998 to increase inter-segment spacing and to place all coupling cavities on the same side for ease of assembly and vacuum pumping. In addition to documentation in the SNS Design Manual [1], this architecture was reported at two conferences $[2,3]$. Parameters of this scheme and the upgrade path to higher power levels are shown in Table 1.

Table 1: Upgrade path in June 1998.

\begin{tabular}{|l|c|c|c|}
\hline Number of: & $1 \mathrm{MW}$ & $2 \mathrm{MW}$ & $4 \mathrm{MW}$ \\
\hline Accelerating Segments & 367 & 367 & 367 \\
\hline RF Modules & 27 & 28 & 31 \\
\hline 805-MHz klystrons & 56 & 64 & 80 \\
\hline
\end{tabular}

*Work supported by the U.S. Department of Energy.

${ }^{+}$Email: hardekopf@lanl.gov
Although this was an improvement over the CDR design because of a reduction in the number of accelerating modules from 56 (one per klystron) to 27 (most modules with two 2.5-MW peak klystrons), re-modularization of some of the segments was still required for each upgrade.

Therefore, as part of a value-engineering exercise by the entire SNS project we decreased the number of klystrons required at $1 \mathrm{MW}$ and reduced the overall linac length by about 20 meters. We accepted that any upgrade would require increasing RF power directly to the 4-MW level, but this upgrade now requires no re-modularization. The extra beam loading from 1-MW to 4-MW power levels results in almost exactly a $50 \%$ increase in overall power (structure plus beam), obtained by adding one klystron to each two-klystron module (see Table 2).

Table 2: Present upgrade path.

\begin{tabular}{|l|c|c|c|}
\hline Number of: & $1 \mathrm{MW}$ & $2 \mathrm{MW}$ & $4 \mathrm{MW}$ \\
\hline Accelerating Segments & 345 & 345 & 345 \\
\hline RF Modules & 26 & 26 & 26 \\
\hline 805-MHz klystrons & 52 & 78 & 78 \\
\hline
\end{tabular}

\section{COST ESTIMATES}

Cost estimates are essential to determine the most effective design approach, define the baseline, obtain funding, and manage the project. We recount here a brief history of the SNS linac cost estimates and compare different methods that have contributed to our current projections.

\subsection{Engineering Validation Package, 1996}

The first official estimate of the SNS linac cost was made in 1996 as part of the Engineering Validation Package (EVP) and led to a cost of $\$ 272 \mathrm{M}$. This was a bottomsup estimate based on Los Alamos experience with similar linacs and component prices. It was not complete because it did not include several project costs such as management. However, the data were useful in setting the parameters of model-based estimates that followed.

\subsection{ASM Model and CDR, 1997}

To take advantage of the work that has recently gone into accelerator modeling codes and databases [4], Los Alamos contracted with Northrop-Grumman Corp. (NGC) in January, 1997 to apply their Accelerator Systems 
Modeling (ASM) code to the SNS linac. ASM incorporates the experience of multiple projects to increase the validity of the code's design options. NGC has also developed an extensive database of component costs that is used in conjunction with ASM to estimate linac costs. The results of the ASM code and database applied to the SNS linac was initially $\$ 456 \mathrm{M}$, but this now included all project costs, including controls, management, and overhead estimates as well as $20 \%$ contingency.

We were able to reduce this model-estimated cost to the official CDR number of $\$ 319$ M by a series of aggressive assumptions that were documented and reviewed. The management challenges included formation of a fully dedicated project team with low overhead and expedited procurement authority. There were also broad discounts taken in materials and installation based on optimization of purchasing through the ORNL construction manager and use of low-cost craft labor for installation at ORNL. CDR numbers in Table 3 have been corrected from the six-year to the seven-year construction schedule recommended by the CDR.

\subsection{Independent Cost Estimate, 1997, and DOE Validation, 1998}

Subsequent changes to this ASM-based estimate were applied as a result of recommendations by the CDR reviewers and by an Independent Cost Evaluation (ICE) team contracted by DOE. The seven-year project cost (TPC) for the linac subsystem became $\$ 330 \mathrm{M}$, which included $20 \%$ contingency as well as the estimated Tennessee tax on purchased components of about \$11 M. Changes were made to the Work Breakdown Structure (WBS) including moving all controls to a separate WBS element and moving the bunch rotator (about \$4 M) from the ring to the linac costs. A significant amount was added to the R\&D budget to do crucial structure modeling and to develop IGBT technology for the RF power system. This was the situation at the time of the June, 1998 DOE validation review, at which time the linac fully-burdened and escalated construction costs were estimated at $\$ 260 \mathrm{M}$ with an additional $\$ 74.5 \mathrm{M}$ for controls, TN tax, and contingency, for a linac TPC contribution of $\$ 334.5 \mathrm{M}$.

\subsection{Bottoms-Up Estimate, 1998-1999}

In the summer of 1998 we conducted a new bottoms-up estimate to verify linac costs. At the same time, we incorporated several value-engineering steps to reduce costs, including shortening the linac and implementing the IGBT converter-modulator RF system based on our initial R\&D studies. The present cost also reflects a reduced number of klystrons at $1 \mathrm{MW}$ as discussed earlier and the addition of a RF power system for the Front-End RFQ (about $\$ 2 \mathrm{M}$ ). As a result of these and previous scope changes, it is not appropriate to directly compare bottomline estimates. Table 3 tracks the cost evolutions for the major categories including the assumptions valid at each major review.

Table 3. Summary of SNS Linac cost estimate (\$M),

\begin{tabular}{|c|c|c|c|c|}
\hline & $\begin{array}{c}\text { EVP } \\
\text { (Dec. 96) }\end{array}$ & $\begin{array}{c}\text { CDR, 7 yr. } \\
\text { (Jun. 97) }\end{array}$ & $\begin{array}{c}\text { Validation } \\
\text { (Jun. 98) }\end{array}$ & $\begin{array}{c}\text { Present } \\
\text { (Jan. 99) }\end{array}$ \\
\hline Linac & 197.6 & 245.3 & 260.0 & 266.6 \\
\hline Controls & 19.6 & 13.8 & 13.8 & 19.4 \\
\hline TN tax \& CM & Not Incl. & 14.6 & 11.2 & 11.2 \\
\hline Contingency & 54.3 & 46.5 & 49.5 & $?$ \\
\hline R\&D & Not Incl. & 7.0 & 16.8 & 13.6 \\
\hline
\end{tabular}

If one corrects for the major changes in scope (e.g., six to seven years, bunch rotator, $402.5-\mathrm{MHz}$ system for RFQ, increased R\&D for hot models and IGBT system), the estimates are not too dissimilar during this two-year period after the CDR, using the different estimating methods. One conclusion that can be drawn is that the linac modeling and cost-estimating tool available with ASM can give a quite dependable first estimate.

\section{COST RISK ANALYSIS}

Near the completion of the present bottoms-up cost estimate, Los Alamos contracted with Hulett \& Associates [5] to complete a cost risk analysis based on the cost data. The purpose of this methodology is to give project managers statistical information gathered from the technical experts in each system as an aid to assessing overall cost risks and which areas are the most vulnerable to cost overruns. The methodology applied was a series of in-depth interviews to obtain a distribution (a triangular distribution was used initially) of best possible, most likely, and worst possible costs at the detailed (WBS level 4 or 5) cost element, as well as obtaining any correlation that might exist between these elements. A standard Monte-Carlo analysis then yielded probable cost distributions at higher WBS levels and probability curves that could help in justifying contingency levels. For the most part, this analysis confirmed that at this stage of the cost estimate a contingency level of $20-25 \%$ is appropriate to achieve probabilities in the $80 \%$ range. More details of this analysis are available in an internal LANL report.

\section{PROJECT SCHEDULING}

Following the CDR, we implemented Primavera Project Planner (P3) to schedule and track project performance. A major factor in this choice was the local experience from several accelerator projects, including APT. Initial cost elements (based on the ASM model) from an Excel spreadsheet were transferred to P3, and the unburdened hours and costs were confirmed as identical to those in the ORNL CDR database. Resource tables were then applied in P3 to more precisely define personnel costs, based on standard rate tables published by Los Alamos for the categories. Official burden (G\&A) rates, procurement recharge, and other standard factors were applied as part of the resource table, and contingency rates published by 
DOE were used. A detailed schedule was produced in P3 that closely matches the project schedule [2] proposed following the CDR. The SNS project has standardized on the use of $\mathrm{P} 3$, and processes are in place to exchange files within the collaboration and to generate work packages for the current year. Because changes in schedule impact cost projections in $\mathrm{P} 3$, however, we are examining other software to contain the baseline cost estimate.

\section{R\&D PROGRAM}

A vigorous $R \& D$ program to prove crucial design concepts is proceeding in parallel with the first two years of construction. The key elements of this program are: completion of the physics design for the cavities [6], cold models and hot models of CCDTL and CCL cavity segments [7], 2.5-MW peak power RF klystrons driven by an IGBT converter-modulator system [8], traveling-wave chopper development [9], and beam dynamics to finalize error tolerances. Cold models have been constructed and measured, and a hot model consisting of two CCL segments will be built this year. Figure 1 shows the envisioned extension of this hot model to include several CCDTL cells next year. Results of the R\&D program are reported in other papers at this conference.

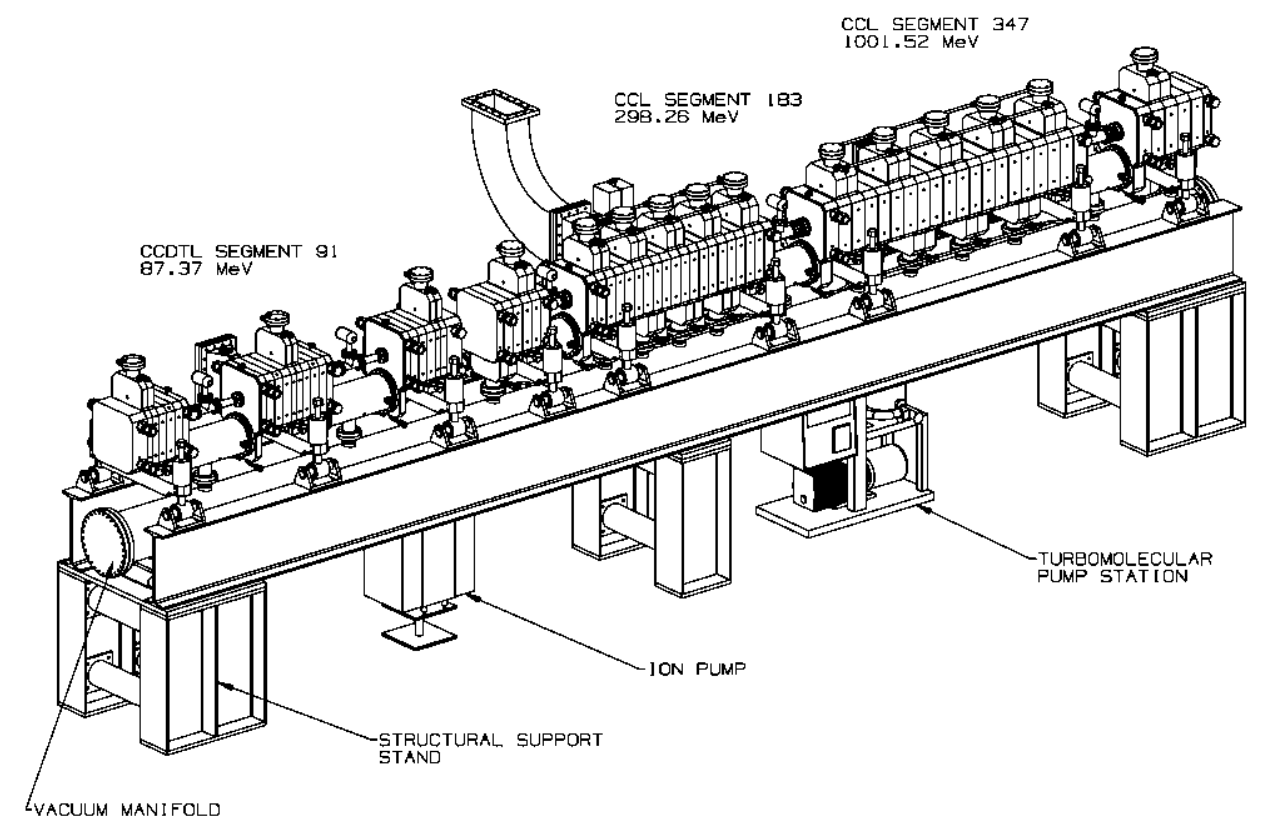

Figure 1. View of the CCDTL and CCL hot-model assembly, to be tested in FY00.

\section{ACKNOWLEDGEMENTS}

We acknowledge the contributions of Andrew Jason, who provided project leadership through the CDR, and Beverly Hartline, who assumed leadership after November 1998. John Rathke and Tim Myers of NGC (now Advanced Energy Systems, Inc.) applied the ASM code to the SNS linac and contributed greatly to initial cost estimates and transfer of data to P3. Stan Schriber contributed to the most recent bottoms-up cost estimate and supported the project during the value-engineering process. Thanks to David Hulett of Hulett \& Associates for the expert advice and assistance on project risk analysis. Finally, the authors acknowledge the expertise and cooperation of the entire SNS linac design team in reaching this stage of the project.

\section{REFERENCES}

[1] SNS Conceptual Design Review, June, 1997, http://www.ornl.gov/ nsns/

[2] R. Hardekopf et al., "Linac Design for the SNS," Second Intl. Topical Meeting on Nuclear Appl. of Accelerator Technology, Gatlinburg, Sept. 1998, 208.

[3] A. Jason et al., "A Linac for the SNS," Linac98, Chicago, August 1998 (in press).

[4] D. Berwald et al., "Parametric Study of Emerging High Power Accelerator Appl. using Accelerator Systems Model (ASM)" Linac96, August 1996, 456.

[5] D. Hulett, see http://www.projectrisk.com/

[6] J. Billen, H Takeda, T. Bhatia, "Linac RF Structures for the SNS," PAC99, New York, March 1999.

[7] N. Bultman et al., "Mechanical Engineering of the Linac for the SNS," PAC99, New York, March 1999.

[8] M. Lynch, P. Tallerico, W. Reass, SNS RF System Overview," PAC99, New York, March 1999.

[9] S Kurennoy, J. Power, and D. Schrage, "MeanderLine Current Structure for SNS Fast Beam Chopper," PAC99, New York, March 1999. 